\title{
STIFFNESS OF RAILWAY SOIL-STEEL STRUCTURES
}

\author{
CZESŁAW MACHELSKI
}

Wrocław University of Technology

\begin{abstract}
The considerable influence of the soil backfill properties and that of the method of compacting it on the stiffness of soilsteel structures is characteristic of the latter. The above factors (exhibiting randomness) become apparent in shell deformation measurements conducted during construction and proof test loading. A definition of soil-shell structure stiffness, calculated on the basis of shell deflection under the service load, is proposed in the paper. It is demonstrated that the stiffness is the inverse of the deflection influence function used in structural mechanics. The moving load methodology is shown to be useful for testing, since it makes it possible to map the shell deflection influence line also in the case of group loads (concentrated forces), as in bridges. The analyzed cases show that the shell's span, geometry (static scheme) and the height of earth fill influence the stiffness of the structure. The soilsteel structure's characteristic parameter in the form of stiffness $k$ is more suitable for assessing the quality of construction works than the proposed in code geometric index $\omega$ applied to beam structures. As shown in the given examples, parameter $k$ is more effective than stiffness parameter $\lambda$ used to estimate the deformation of soil-steel structures under construction. Although the examples concern railway structures, the methodology proposed in the paper is suitable also for road bridges.
\end{abstract}

Key words: soil-steel structure, numerical analysis, stiffness of structure, proof test

\section{INTRODUCTION}

Soil-steel structures are conventionally divided into stiff and flexible structures, depending on the value of dimensionless Duncan parameter $\lambda[1],[2]$ and Klein parameter $n$ [3], [4]. If the relation

$$
\lambda=E_{g} \frac{L^{3}}{E I / a}>100
$$

is satisfied, the structure is classified as flexible. In formula (1) the technical parameters are: $E_{\mathrm{g}}$ - the modulus of soil elasticity, EI/a - the flexural stiffness of the shell corrugated plate circumferential strip having width $a, L-$ the span of the shell. Thus index $\lambda$ characterizes the flexibility of a buried shell. Soil-steel bridge structures are made of corrugated plates and usually have higher flexibility $\lambda>10000$. Not much lower flexibility characterizes structures built up from precast concrete units [4].

Index $\lambda$ is used to calculate shell deformations during construction [4], [5] and it is of little use for calculating structures subjected to service loads. It is shown in this paper that the geometry of the shell (Fig. 1), the thickness of the earth fill in the crown and pavement, and the type of load (configuration of forces in a vehicle) are of major importance for bridges. The above factors are not taken into account in $\lambda$.

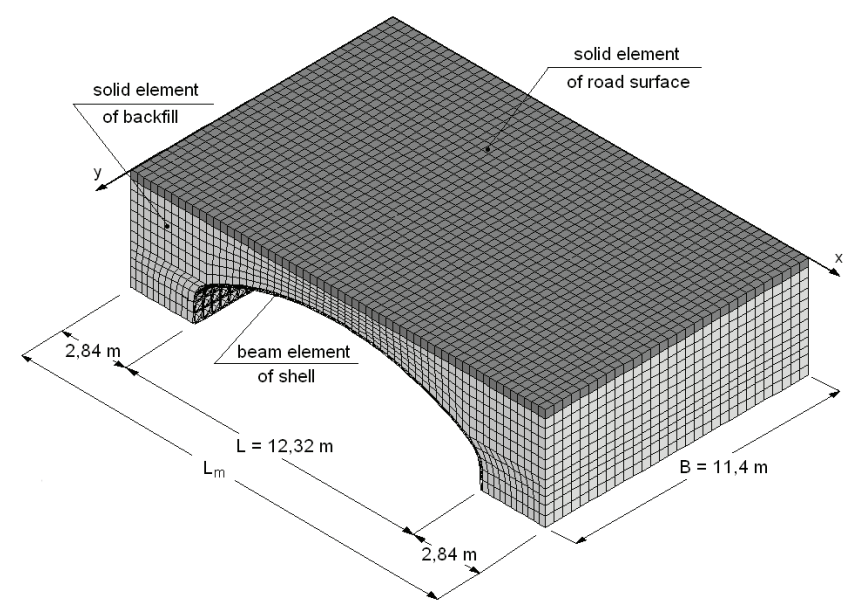

Fig. 1. Exemplary FEM model of soil-steel structure [2]

At the design stage and then during proof test loads the stiffness of a bridge structure is verified using the service limit state condition given in the standard, expressed by the dimensionless geometric index

$$
\omega=\frac{w}{L} .
$$

In formula (2), $w$ is the deflection of a bridge structure (e.g., its main girder or stringer). Index $\omega$ is calculated in the case of beam structures. The value of $w$ is related to the span $L$ under maximum load $Q$. It is 
compared with the permissible value given in standards (e.g., 1/600) for a given type of bridge structure or its element and the structural material. However, at the construction stage the deformations of corrugated plate shells are much larger, reaching $\omega>1 / 40$ [4]. The stiffness of soil-steel structures expressed by index $\omega$, as for bridges, is comparable with that of classic concrete and steel structures.

In this paper, it is proposed to define bridge structure stiffness as a ratio of concentrated force $P$ to displacement $w$ caused by this force, as in the formula

$$
k=\frac{P}{w} \quad[\mathrm{kN} / \mathrm{mm}] .
$$

In the case considered, a linear model of the structure, i.e., linear relation $w(P)$ is assumed. The minimum value of $k$ as a characteristic of the structure, i.e., resulting from the maximum displacement under given load $P$, is of major importance. In the case of bridges, such a location of the force $P$ on the bridge deck is sought at which maximum displacement $w$ occurs. The influence function is used in this approach [6].

When the force $P$ changes its location along a straight line, as in railway bridges, the problem reduces to the form shown in Fig. 2. According to the definition of an influence line, displacement $w$ is obtained from the relation

$$
w=P \cdot \eta
$$

and after substituting it into (3) one gets the formula

$$
k=\frac{1}{\eta} \quad[\mathrm{kN} / \mathrm{mm}]
$$

Therefore stiffness $k$ is the inverse of the ordinate of displacement influence function $\eta$. Thus $\eta$ is also an index, but one which describes the flexibility of a structure, as $\lambda$ in Eq. (1). It follows from relation (5) and Fig. 2 that the value of $k$ depends on the shape of the influence function and so on the structure's geometry, stiffness distribution EI and the structure's support conditions.

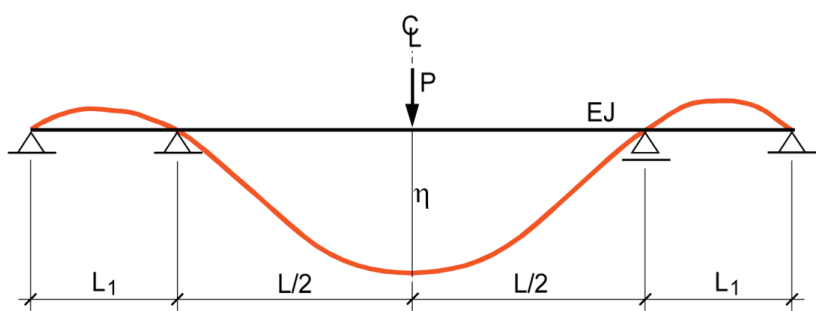

Fig. 2. Influence line of beam deflection in midspan
According to Betti's reciprocity principle, the ordinates of the deflection influence function are also the deflections of the structure's points under a unit force load $P=1$, as shown in Fig. 2. Thus the determination of the value of $k$ consists in searching for the maximum deflection under the force moving within the defined area (deck area of a road bridge) or along a line (a railway bridge track). In the case of soil-steel railway bridges, this point is uniquely located, i.e., above the shell crown and under the railway track. Thus the problem is reduced to the simple solution consisting in determining the deflection line along the railway track.

\section{STIFFNESS OF BEAM STRUCTURES}

No concentrated forces $P$ appear in practical loads acting on structures. Therefore force configurations defined as load $Q$ are used and the structure stiffness is calculated from the formula

$$
k_{q}=\frac{Q}{w} \quad[\mathrm{kN} / \mathrm{mm}] .
$$

In the case of a group of $n$ concentrated forces, formula (6) takes the following general form

$$
k_{q}=\frac{\sum_{i=1}^{n} P_{i}}{\sum_{i=1}^{n} P_{i} \eta_{i}}
$$

and when the forces are identical, i.e., $P=P_{i}$, one gets

$$
k_{q}=\frac{n}{\sum_{i=1}^{n} \eta_{i}}>k .
$$

Since by assumption $\eta>\eta_{i}$, as in Fig. 3, the structure's stiffness calculated for the configuration of forces will always be lower than the value of $k$ calculated from formula (5), thus $k_{q}>k$.

In the case of load distributed along a section with the length

$$
L_{q}=L-2 a,
$$

from formula (6), adopting the symbols given in Fig. 3, one gets

$$
k_{q}=\frac{q L_{q}}{q A_{q}}=\frac{L_{q}}{A_{q}}>k
$$


Relation $k_{q}>k$ results from the geometrical relation given in Fig. 3, i.e. from $A_{q} / L_{q}<\eta$.

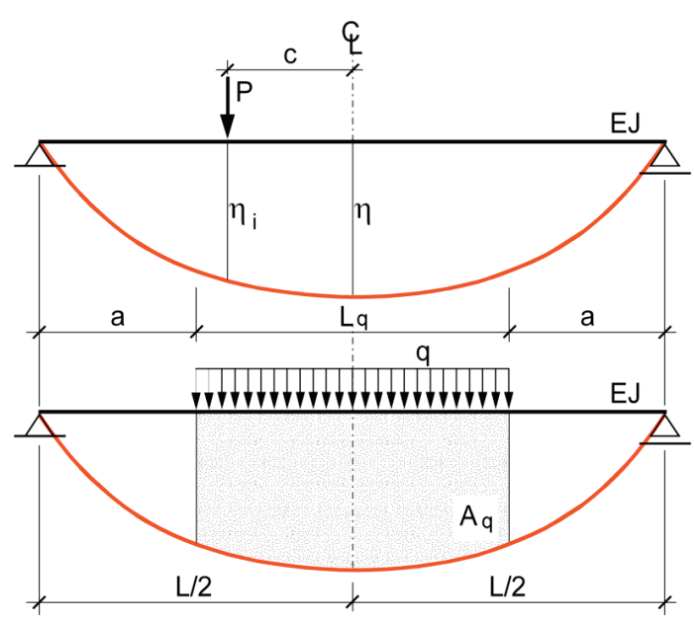

Fig. 3. Parameters of deflection influence line of simply supported beam

Stiffness $k_{\mathrm{q}}$ of beam structures with stiffness $E I$ and span $L$, considered below, is expressed in the general form as

$$
k_{q}=\alpha \frac{E I}{L^{3}} .
$$

Formula (11) is similar to that of equation (1). However, one should note that EI in (11) represents the stiffness of a structure, not that of a buried corrugated plate as in (1).

The influence of the static scheme and that of the load configuration on the stiffness of a structure is analyzed below for the simply supported beam. Calculated values of $k_{q}$ are presented in Table 1 .

Scheme 1: the force is located at distance $c$ from the midspan, as in Fig. 3

$$
\eta_{i}=\eta\left\{\frac{L+2 c}{2 L}\left[3-\left(\frac{L+2 c}{L}\right)^{2}\right]+8\left(\frac{c}{L}\right)^{3}\right\} .
$$

Figure 4 shows the diagram of the relation

$$
K(c)=\eta / \eta_{i}
$$

when

$$
\eta=48 \frac{E I}{L^{3}} .
$$

Scheme 2: a group of three forces located at distance $c$ from the midspan

$$
k_{q}=\frac{3 P}{P\left(2 \eta_{i}+\eta\right)}=\frac{3}{2 \eta_{i}+\eta} .
$$

Scheme 3: load distributed along section with length $L_{q}$. Figure 4 shows the diagram of the relation

$$
K(a)=\eta \frac{L_{q}}{A_{q}} .
$$

Hence the diagram given in Fig. 4, based on equation (16), has the form

$$
K(a)=\frac{1-\frac{2 a}{L}}{\frac{5}{8}-\left(\frac{a}{L}\right)^{2}\left[3-2\left(\frac{a}{L}\right)^{2}\right]} .
$$

Scheme 4: load distributed along the beam. When $A_{o}$ is the surface area under the diagram of the deflection influence line of the beam in its midspan, one gets the constant value

$$
\frac{A_{o}}{L}=\frac{384}{5} \frac{E I}{L^{3}} .
$$

Table 1. Load schemes and stiffness of simply supported beam

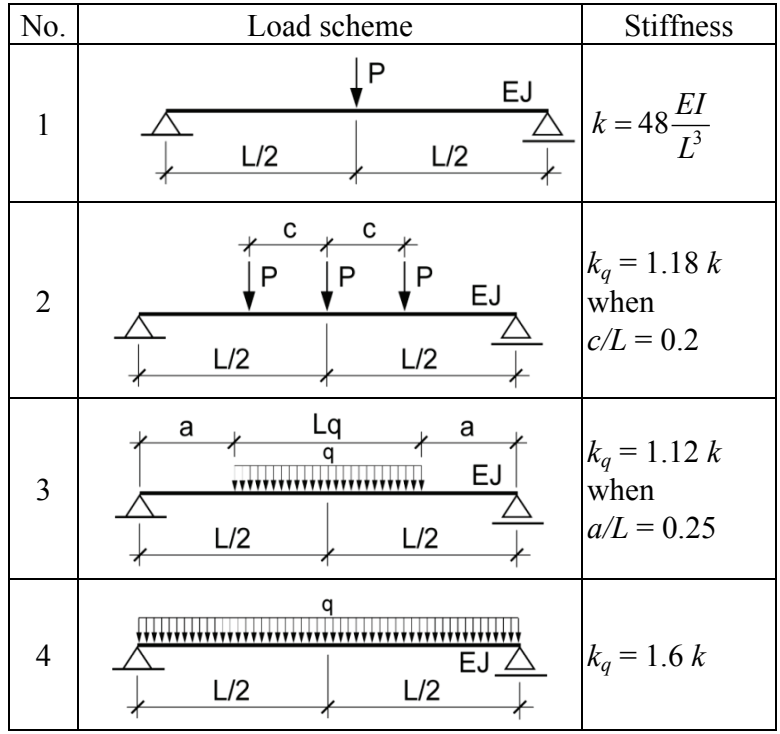

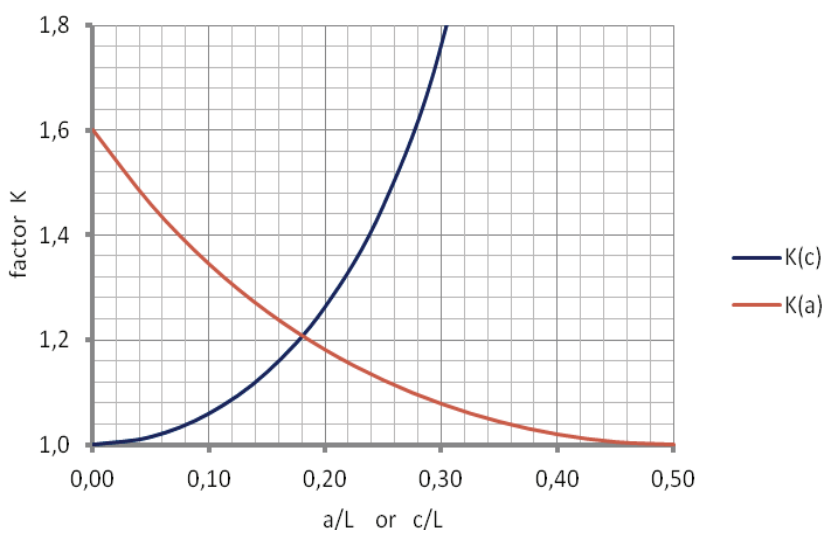

Fig. 4. Diagram of relation $K(a)$ and $K(c)$ 
In the case of the static scheme of a multi-span beam (Fig. 2), the result of calculating $k$ from (3) depends on the ratio $L_{1} / L$. When $L_{1} / L=0.2$, one gets $\alpha=141.913$, i.e., a result intermediate between $\alpha=48$ (simply supported beam) and $\alpha=192$ (fixed beam).

\section{STIFFNESS \\ OF SOIL-STEEL STRUCTURE UNDER CONSTRUCTION}

Exemplary results of measurements conducted during loading a soil-steel structure with the simplest configuration of forces: a two-axle vehicle, carried out by Pettersson [7], are presented below. The structure was built especially for the test purposes. The closed cross-section of the shell had a drop-like shape (VM22) and the characteristic dimensions: span $L=6.04 \mathrm{~m}$ and height $h=4.55 \mathrm{~m}$. The analyzed structure was made from MP $200 \times 55 \times 2.93$ low-profile metal plates. A loader with the specification shown in Fig. 5 was used in the tests. The test plan assumed that the load would change its position in a quasi-static way and drive along the axis of the roadway especially prepared (without pavement) for the tests.
Figure 5 shows the measured deflection in the shell crown [2], [4], [7]. The position of the vehicle front wheel $(2 P=221 \mathrm{kN})$ relative to the shell crown is marked on the horizontal axis. When $x=0$, this wheel is over the shell crown, as shown in Fig. 5. The second increase in deflection (Fig. 5) results from the loading with the other loader's wheel $\left(2 P_{1}=\right.$ $69 \mathrm{kN}$ ) in the position above the shell crown, i.e., when $x=3.4 \mathrm{~m}$.

If the wheel base is large in comparison with the culvert span, as in the case considered, one can draw deflection influence lines $\eta$ on the basis of the deflection diagram presented in [7]. It is then assumed that both forces from the wheels of the axle $2 \mathrm{P}$ are identical [7]. Figure 5 shows two lines, which coincide in the range of $-5<x<-1.5 \mathrm{~m}$, when the second axle of the vehicle is situated outside the active part of the soil backfill. Then $w(x)=2 P \cdot \eta$. Another common point of the diagrams is the vehicle's position when $x=-2.8+3.4=0.6 \mathrm{~m}$. Then the vehicle's second axle is situated over the zero ordinate of the influence line and $w(x)=2 P \cdot \eta$. When $x=2.8 \mathrm{~m}$, the first axle is over the zero ordinate, while the second axle is in the position $-3.4+2.8=-0.6 \mathrm{~m}$. Then

$$
w(x=2.8)=69 / 221 \cdot 1.4=0.437 \mathrm{~mm} .
$$

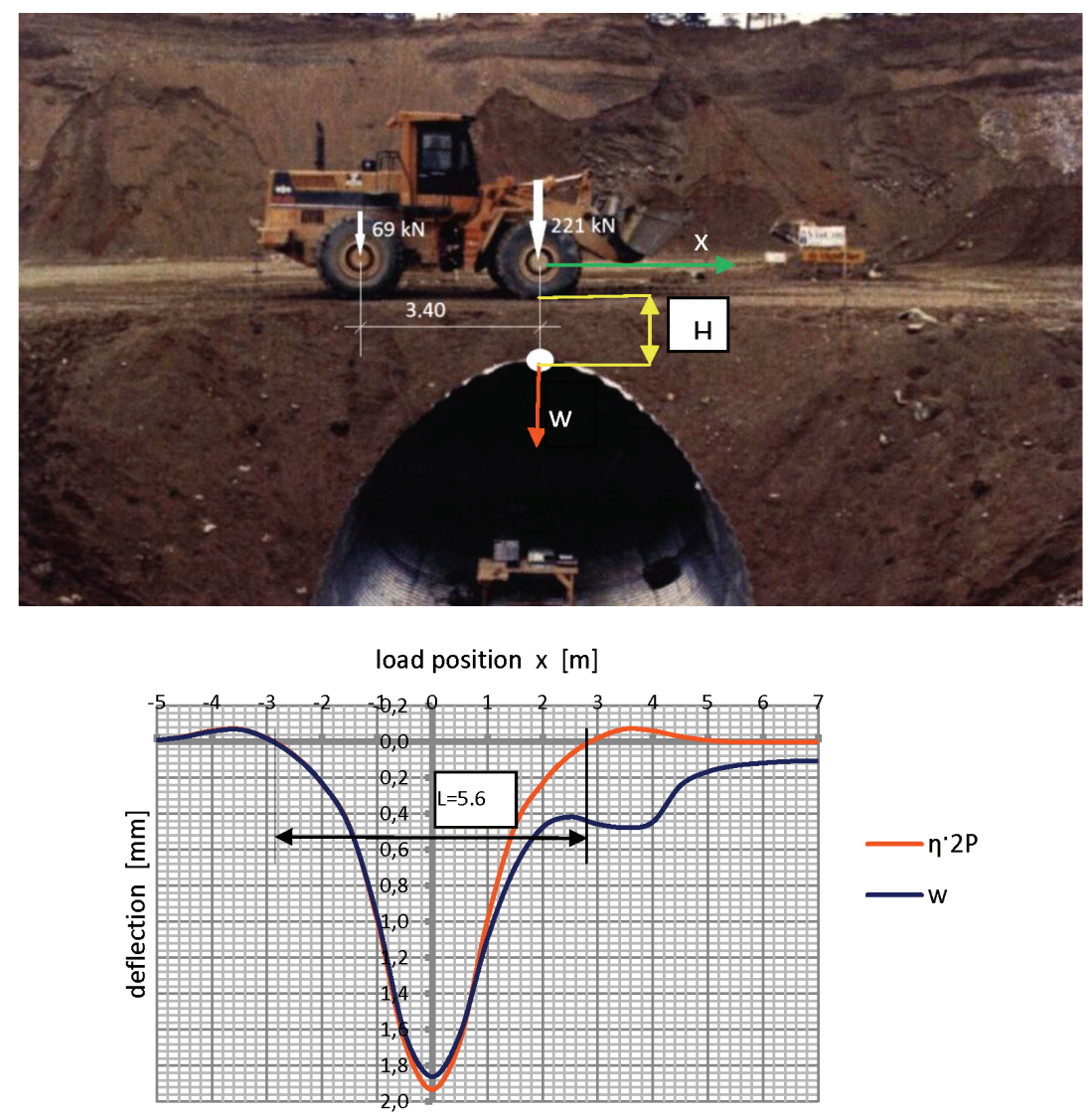

Fig. 5. Changes in shell crown deflection $w$ during loader passage and deflection influence line $\eta$ 
Table 2. Changes in structure stiffness during construction

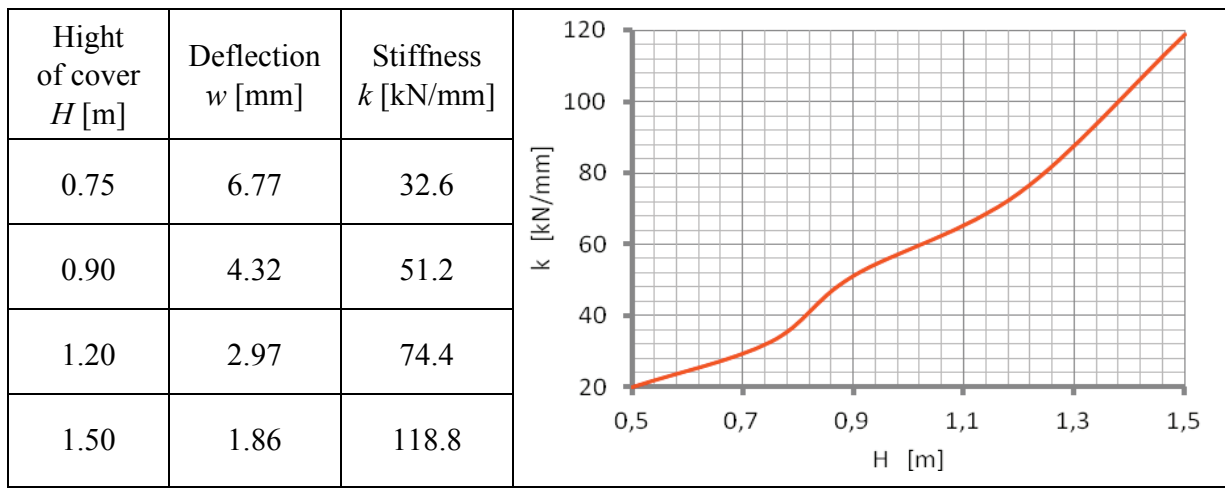

In general, when the two forces are in any position, values of $2 P \cdot \eta(x)$ are calculated from the equation

$$
w(x)=2 P \cdot \eta(x)+2 P_{1} \cdot \eta(x-3.4)
$$

hence

$$
2 P \cdot \eta(x)=w(x)-2 P_{1} \cdot \eta(x-3.4) .
$$

Deflection $w(\mathrm{x})$ and the previously determined ordinate of deflection influence line $\eta(x=-3.4)$ are defined in equation (20), according to which the deflection of the shell crown, when $2 P$ is situated over it, i.e., at point $w(x=0)=1.86 \mathrm{~mm}$, is equal to

$$
2 P \cdot \eta(x=0)=1.86-0.072 \cdot 69 / 221=1.882 \mathrm{~mm} .
$$

In the tests [7], deflection measurements were carried out during construction at different values of soil backfill thickness $H$ (i.e., the thickness of the backfill over the crown). On this basis the changes in structural stiffness as a function of $k_{\mathrm{q}}(H)$ were calculated and are given in Table 2. Because of the specific structure of soil-steel bridges, the earth backfill (particularly, its thickness $H$ as indicated by the results presented in Table 2) has a significant influence on their stiffness [8], [9]. In the case of road bridges, the value of $k$ is significantly influenced by, e.g., the asphalt pavement [2], [4], [10].

In the case of beam static schemes, influence line length $L$ is also their span, as shown in Fig. 2. The shape of the deflection influence line in Fig. 2 is similar to the longitudinal profile of the shell deflection influence surface in the soil-steel structure, shown in Fig. 5. The $L$ assumed for structure stiffness calculations is usually close to the larger horizontal dimension (span) of the shell.

\section{STIFFNESS OF RAILWAY STRUCTURE ACCORDING TO STANDARDS}

In the case of short-span structures, such as soilsteel structures, deflection of the shell is not influenced by the total vehicle weight $Q_{n}$, but by the vehicle's configuration of axles, wheel base $c$ and axle load $P$. Taking into account relations (2) and (6) one gets

$$
k_{n}=\frac{Q_{n}}{\omega \cdot L} \approx \frac{P}{\omega \cdot c}=\frac{q_{n}}{\omega} .
$$

In formula (21), $q_{n}=P / c$ is a force uniformly distributed along the length of the track. In the analyzed structures the concentrated axle load is distributed through the track superstructure, as shown in Fig. 6.

In the case of the railway loads considered, for standard scheme UIC71 one gets

$$
q_{n}=\frac{P}{c}=\frac{250}{1.60} \alpha_{k} .
$$

Using formulas (21) and (22) one can calculate the permissible (minimum) stiffness of a railway bridge. Assuming that the railway structures considered were designed for permissible index $\omega=1 / 800$ (as for high speed trains), one gets

$$
k_{U I C}=\frac{q}{\omega}=\frac{250}{1.60} \alpha_{k} 800 \cdot 10^{-3}=125 \alpha_{k} \mathrm{kN} / \mathrm{mm} .
$$

Stiffness $k_{U I C}$ determined in this way has a general applicability, since it applies both to classic beam bridges and soil-steel bridges. In the latter case, a small span $L$ of the analyzed element, due to the simplification used in formula (21), is assumed, i.e.,

$$
Q_{n} / L \approx P / c .
$$




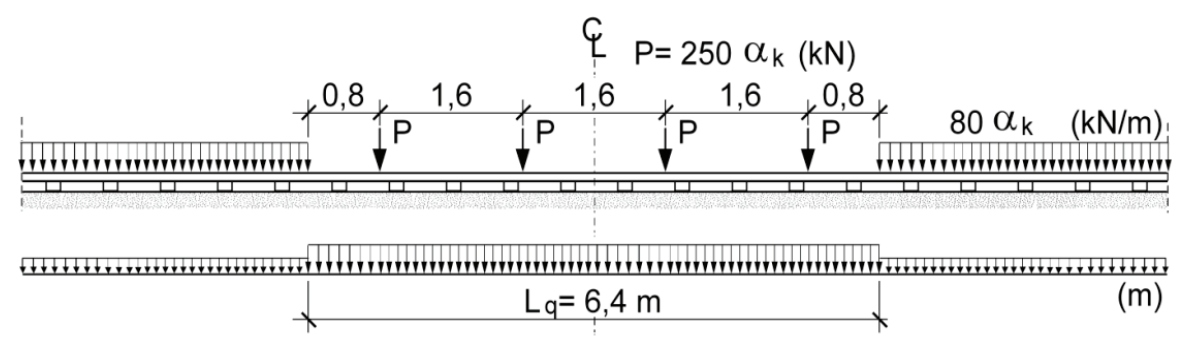

Fig. 6. Distribution of UIC71 load through track superstructure

\section{TESTING STIFFNESS OF RAILWAY STRUCTURE}

The shell of the soil-steel bridge in Prabuty was made of Super Cor SC $380 \times 140 \times 7$ corrugated plates [2], [4] with sectional overlays (plates shifted by one panel) made of SC $380 \times 140 \times 5.5$ corrugated plates. According to the manufacturer's specifications, the circumferential SC-35B shell strip had a box geometry [2], [4]. The shell's characteristic dimensions were: span $L=7.945 \mathrm{~m}$, height $h=2.370 \mathrm{~m}$ and upper radius of curvature $R=8.820 \mathrm{~m}$. Its upper width $B_{\mathrm{g}}=13.8 \mathrm{~m}$ and lower width $B_{\mathrm{d}}=21.36 \mathrm{~m}$. The structure was characterized by a very small structural height $h_{k}=1.20 \mathrm{~m}$ calculated according to

$$
h_{k}=H+h_{n}
$$

which, taking into account the total thickness of the $60 \mathrm{E} 1$ track superstructure on ballast and pre-stressed concrete sleepers, gives a $0.95 \mathrm{~m}$ thick layer, resulting in the small earth fill thickness in the crown: $H=1.20-0.95=0.25 \mathrm{~m}$.

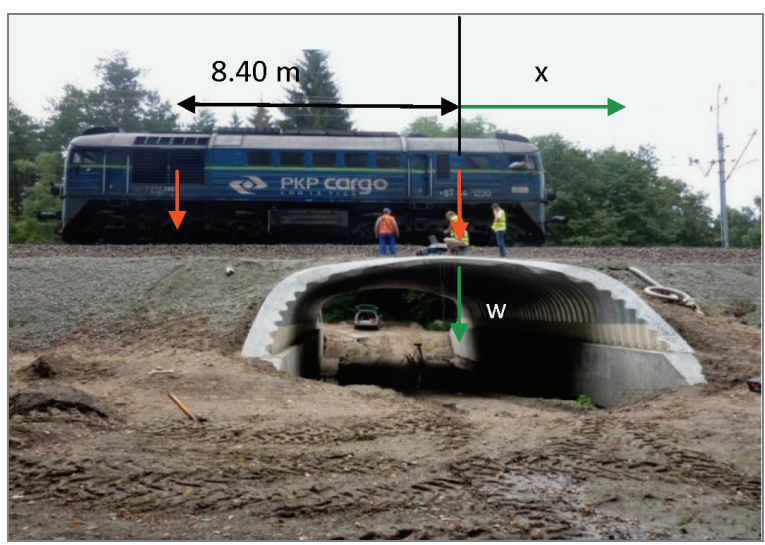

Fig. 7. Loading soil-steel structure with locomotive

The structure was designed for railway load class $k+2$. The ST44 locomotive shown in Fig. 7 was used in the proof test load. Inductive sensors with a reading range of $0-50 \mathrm{~mm}$ and a sensitivity of $0.01 \mathrm{~mm}$ were used to measure deflections. The quasi-static load position change methodology, consisting in the locomotive passage at a constant step, in this case amounting to two sleepers, i.e., about $1.3 \mathrm{~m}$, was adopted. In these positions the measurements were automatically recorded by a computer and diagrams of the variation in shell crown deflection during the locomotive passage were created on their basis.

Loading with multi-axial rail vehicles is used in proof tests. In the case of short-span structures, such as soil-steel bridges, the shell deflection results only from some part of the total load. Therefore only $n$ vehicle axles situated on the deflection influence line contribute to the maximum deflection of the shell crown, as expressed by the formula

$$
k_{q}=\frac{Q}{w}=n \frac{P}{w}=n c \frac{P}{c w}=\frac{q L_{q}}{w},
$$

where $P$ is the axle load. Typically the number of locomotive carriage axles is $n=3$ (see Fig. 7). The effective length of loading with the ST44 locomotive is

$$
L_{q}=3 \cdot 2.10=6.30 \mathrm{~m}
$$

and is close to the value shown in Fig. 7, whereas loading intensity

$$
q(S T 44)=\frac{P}{c}=\frac{190.5}{2.10}=90.7 \mathrm{kN} / \mathrm{m}
$$

is approximately half lower than that arising from the standard load UIC71.

The stiffness of the structure, calculated on the basis of elastic deflection $w=3.85 \mathrm{~mm}$ (Fig. 8), is

$$
k_{q}=n \frac{P}{w}=3 \frac{190.5}{3.85}=148.4 \mathrm{kN} / \mathrm{mm} \text {. }
$$

The range of effectiveness of load $Q$ is determined on the basis of the length (and shape) of the deflection line for the load changing its position. Since no effects of single axles are visible on the deflection line, the 
group of forces in the locomotive carriage can be treated as a distributed load. Section $L_{\mathrm{q}}$ is close to deflection influence line length $L$ given in Fig. 8. This justifies the assumption of $n=3$ in formula (21).

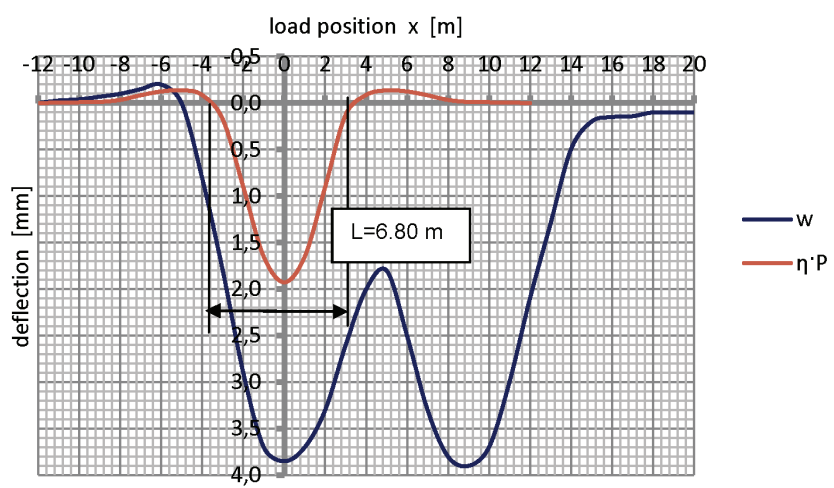

Fig. 8. Deflection change $w$ and shape of shell crown deflection influence line $\eta$ load-bearing elements. In typical bridges these are elements which distribute the concentrated load from the wheels of vehicles. Thus the physical characteristics of the soil backfill and the method of placing and compacting it are important for the stiffness of the structure. In this paper, it is proposed that the stiffness of a soil-steel structure determined on the basis of the proof test loads results can be an efficient parameter used for assessing the quality of the construction works of this type of structures. The results of analysis of other structures, presented in Table 3, indicate that the parameter $k_{q}$, calculated from (6), is a better parameter than the geometric index $\omega$ assumed in the design guidelines, defined by formula (2). Parameter $k_{q}$ does not depend on the intensity of the load $Q$, as in (6).

The moving load methodology presented in this paper and described in [10] is useful for assessing

Table 3. Characteristics of tested soil-steel structures

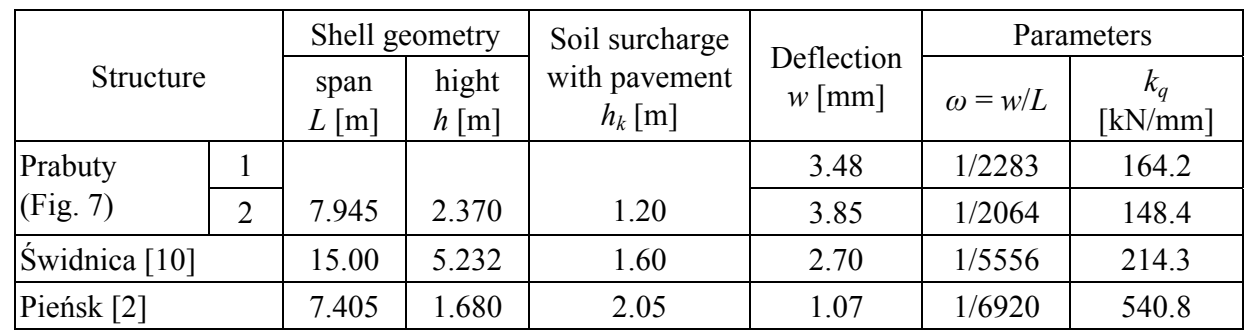

In the case of a short-span structure (Figs. 7 and 8), the shape of the deflection influence line can be represented also for the locomotive load. Then there is not a single force, but two sections of a distributed load with a $2.4 \mathrm{~m}$ break between them. The influence line in this case was related to load $P$ in order to show the deflection influence line $\eta(x)$.

Thus it is not necessary to model a soil-steel structure loaded with the configuration of rail vehicle forces in order to compare the standard permissible stiffness calculated from formula (23) and the experimental one calculated from relation (25). This greatly facilitates the proof testing of railway soil-steel structures. Therefore structure stiffness $k_{q}$ calculated from (26) using the proof test results can be the basis for assessing the quality of the construction works.

\section{CONCLUSIONS}

As opposed to classic bridges, the characteristic feature of soil-steel structures is the significant influence of the earth fill and the pavement acting as the

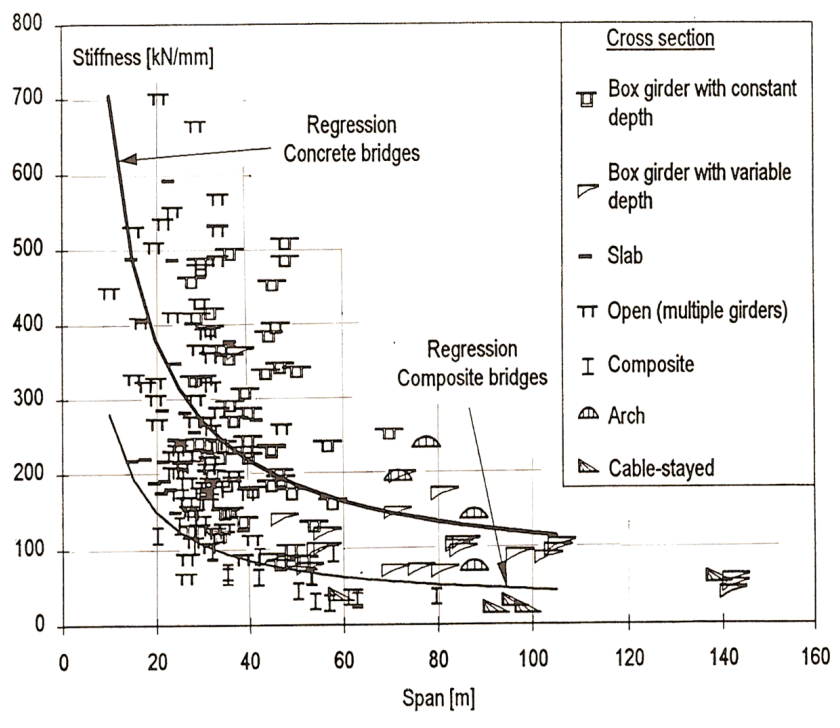

Fig. 9. Stiffness as function of bridge span [12]

the performance of the shell in a structure. It enables mapping of the shell deflection influence line and determination of the number $(n)$ of effective axle loads, assumed in formula (25). As shown in 
the provided test results, shell span $L$ is not the only characteristic parameter of soil-steel structures.

Stiffness of a structure can also be assessed in the case of dynamic tests - as the so-called static background. Figure 9 shows test results of two hundred bridges of different type and static scheme built in Switzerland [12]. These results indicate that the stiffness of soil-steel structures is similar to the stiffness of short-span steel-concrete composite bridges.

\section{REFERENCES}

[1] Duncan J.M., Behaviour and Design of Long Span Metal Culverts, ASCE, Convention "Soil-Structure Interaction for Shallow Foundations and Buried Structures", San Francisco, USA, October 1977.

[2] MACHELSKI C., Modelowanie obiektów gruntowo-powtokowych. Modelling of soil-steel bridge structures, Dolnośląskie Wydawnictwo Edukacyjne, Wrocław 2008, (in Polish).

[3] Madryas C., Kolonko A., Wysocki L., Konstrukcje przewodów kanalizacyjnych. Sewer structures, Wrocław University of Technology Publishing House, Wrocław 2002, (in Polish).

[4] MAChelski C., Budowa konstrukcji gruntowo-powtokowych. The construction of soil-steel structures, Dolnośląskie Wydawnictwo Edukacyjne, Wrocław 2013, (in Polish).
[5] Machelski C., Michalski J.B., Janusz L., Deformation Factors of Buried Corrugated Structures, Journal of the Research Board, Transportation Research Board of Nationals Academies, Washington D.C., 2009, 70-75.

[6] MaChelsKi C., Kinematic method for the determination of influence function of internal forces in the steel shell of soilsteel Bridges, Studia Geotechnica et Mechanica, 2010, No. 3, 27-40.

[7] Pettersson L., Full Scale Tests and Structural Evaluation of Soil Steel Flexible Culverts with low High of Cover, Doctoral Thesis in Civil and Architectural Engineering Stockholm, 2007.

[8] Bayoglu Flaner E., Sundquist H., Full-scale testing of two corrugated steel box culverts with different crown stiffness, Archives of Institute of Civil Engineering, 2007, No 1.

[9] MANKo Z., BęBĘN D., Influence of road pavement on behaviour of soil-steel bridge structure, Der Stahlbau, 2007, 76, Heft 12, 905-915.

[10] Machelski C., Dependence of deformation of soil-shell structure on the direction of load passage, Bridge and Road, 2014, 13, 223-233.

[11] BĘBEN D., Numerical analysis of soil-steel bridge structure, The Baltic Journal of Road and Bridge Engineering, 2009, 4, $13-21$.

[12] Burdet O., Corthay S., Static and dynamic load testing of Swiss bridges, International Bridge Conference Warsaw '94. Proceedings. June 20-22, 1994, Vol. 2. Analytical evaluation of bridges bridge management system. Warszawa: IBDiM, 1994, 13-22. 